\title{
ENTREVISTA
}

\section{ENTREVISTA COM A PROFESSORA MARIA ELIETE SANTIAGO}

\author{
Marinaide Freitas ${ }^{1}$ \\ Luís Alcoforado ${ }^{2}$ \\ Edinólia Lima Portela ${ }^{3}$
}

\section{RESUMO}

Esta entrevista foi concedida com exclusividade pela professora e pesquisadora doutora Maria Eliete Santiago à Revista Educação e Emancipação para o Dossiê EDUCAÇÃO DE PESSOAS JOVENS E ADULTAS: SUJEITOS, CULTURAS E PRÁTICAS EDUCATIVAS", comemorativo dos 100 anos de nascimento do educador Paulo Freire. A entrevistada é pernambucana como o educador e além de ter sido sua aluna e orientanda, teve o privilégio de uma convivência pessoal de amizade que permaneceu por muitos anos, enquanto Paulo Freire partiu deste plano terrestre imortalizando-se por meio do legado que deixou. A professora Eliete Santigo, como assim é conhecida, tem mestrado em Educação e Currículo pela PUC/SP e doutorado em Educação pela Universidade de Paris V - Rene Descarte. É professora titular da Universidade Federal de Pernambuco - UFPE, Centro de

1 Doutora em educação. Professora da Universidade Federal de Alagoas (UFAL) do Programa de Pós-Graduação em Educação Brasileira (PPGE) e do curso de Pedagogia. Coordenadora do Núcleo de Estudo, Pesquisa e Extensão sobre Alfabetização (Nepeal), Cedu/Ufal. Membro do GT 18 - Educação de Pessoas Jovens e Adultos da Anped e também, membro do Fórum Alagoano de Educação de Jovens e Adultos (FAEJA). ORCID: https://orcid.org/0000-0003-3659-4165 E-mail: marinaide.queiroz@cedu.ufal.br

2 Doutor em Ciências da Educação. Professor da Faculdade de Psicologia e de Ciências da Educação da Universidade de Coimbra-UC. ORCID: https://orcid.org/0000-0003-44257011E-mail: lalcoforado@fpce.uc.pt

${ }^{3}$ Doutora em Educação. Professora Associada do Curso de Pedagogia e do Programa de Pós Graduação da Universidade Federal do Maranhão - UFMA. Integrante do grupo de Pesquisa: Escola Currículo e Formação Docente PPG em Educação/ UFMA. Membro do Fórum de Educação de Jovens e Adultos do Maranhão. ORCID: https://orcid.org/00000001-9678-322X. E-mail: edinolia.portela@ufma.br. 
Educação, vinculada ao Programa de Pós-Graduação em Educação. Coordenadora da Cátedra Paulo Freire da UFPE, sócia fundadora do Centro Paulo Freire - estudos e pesquisas, integra a Rede Freireana de Pesquisadores e desenvolve estudos sobre formação de professores e prática pedagógica, questões étnico-raciais e pedagogia freireana.

Palavras-chave: Compreensão de mundo. Justiça social. Humanização.

\section{ABSTRACT}

This interview was given exclusively by professor and doctor researcher Maria Eliete Santiago to the periodical Educação e Emancipação for the Dossier "EDUCATION OF YOUNG AND ADULT PEOPLE: SUBJECTS, CULTURES AND EDUCATIONAL PRACTICES", celebrating the 100th anniversary of Paulo Freire's birth. The interviewee is from Pernambuco, as was the educator, and besides being his student and guided by him, had the privilege of having a personal friendship that lasted for many years, while Paulo Freire left this earthly plane, immortalizing himself through the legacy he left behind. Professor Eliete Santigo, as she is known, has a master's degree in Education and Curriculum from PUC/SP and a doctorate in Education from the University of Paris $V$ - Rene Descarte. She is a titular professor at the Federal University of Pernambuco - UFPE, Education Center, linked to the Post-Graduation Program in Education. She is coordinator of the Paulo Freire Chair at UFPE, founding member of the Paulo Freire Center - Studies and Research, member of the Freirean Network of Researchers and develops studies on teacher trainning and pedagogical practice, ethno-racial issues and Freirean pedagogy.

Keywords: Understanding the world. Social justice. Humanization. 


\section{RESUMEN}

Esta entrevista fue concedida en exclusiva por la profesora e investigadora de doctorado Maria Eliete Santiago a la Revista Educação e Emancipação para el Dossier sobre la EDUCACIÓN DE LOS JÓVENES Y ADULTOS: SUJETOS, CULTURAS Y PRÁCTICAS EDUCATIVAS", en conmemoración de los 100 años del nacimiento del educador Paulo Freire. La entrevistada es pernambucana como el educador y además de haber sido su alumna y estudiante, tuvo el privilegio de una amistad personal que duró muchos años, mientras que Paulo Freire dejó este plano terrenal y se inmortalizó a través del legado que dejó. La profesora Eliete Santigo, como se la conoce, tiene un máster en Educación y Currículo por la PUC/SP y un doctorado en Educación por la Universidad de París V - René Descarte. Es profesora titular de la Universidad Federal de Pernambuco - UFPE, Centro de Educación, vinculada al Programa de Postgrado en Educación. Es coordinadora de la Cátedra Paulo Freire en la UFPE, miembro fundadora del Centro Paulo Freire - Estudios e Investigaciones, miembro de la Red Freireana de Investigadores y desarrolla estudios sobre formación docente y práctica pedagógica, cuestiones étnicoraciales y pedagogía freireana.

Palabras clave: Entender el mundo. La justicia social. Humanización

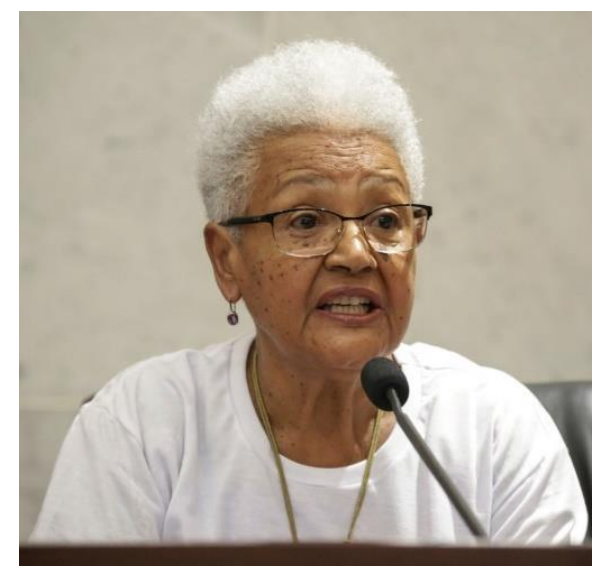

Fonte: Arquivo pessoal da entrevistada 
Entrevistadores: Sabemos que a Professora conviveu com Paulo Freire. Poderia nos falar sobre sua relação com ele, pondo em destaque a sua personalidade, suas ações como pessoa e acadêmico e como as várias gerações de professores e pesquisadores que não o conheceram podem visitar ou revisitar o seu legado na perspectiva de recriá-lo e imortalizá-lo nas futuras gerações de educadores?

Maria Eliete Santiago: Minha relação com o professor Paulo Freire, inicialmente foi como aluna, seguida de orientanda, depois foi se transformando numa grande amizade que durou até a sua permanência neste plano terrestre. Hoje, tenho uma lembrança viva e um compromisso político pedagógico com seus referenciais. Essa relação teve início em março de 1982, na Pontifícia Universidade Católica de São Paulo-PUC/SP, no Programa de Supervisão e Currículo, hoje Educação e Currículo. Foi uma boa caminhada, também partilhada com a professora Ana Saul, companheira de sonhos e caminhadas. Com Paulo Freire tive a oportunidade de vivenciar princípios básicos como ética, rigorosidade, amorosidade e solidariedade que orientam e estão presentes na sua obra. Testemunhei sua coerência efetiva e inabalável. Paulo Freire é um testemunho ético, de humanização, resistência e esperança.

Entrevistadores: Como situar Paulo Freire, quando expressava aos seus pares, pesquisadores, educadores e militantes: "não me copiem, me recriem"?

Maria Eliete Santiago Leio como um convite à coerência. Vejo como uma atitude coerente do professor Paulo Freire. Paulo Freire formulou uma concepção de educação que tem na base um conjunto de princípios que orientam o que fazer educativo. Teceu com reflexão e prática, uma educação que se fundamenta e se orienta pela compreensão que o ser humano é sujeito do processo de conhecimento. Desse modo, Paulo Freire não poderia pensar/sugerir/recomendar a transferência ou a repetição da sua pedagogia; fazer uso das mesmas temáticas; construir e analisar as mesmas tramas. Por isso, compreendo que recriar Paulo Freire é fazer 
novas leituras de mundo, é atentar para questões sociais recolocadas e novas demandas sociais, assim como identificar novos temas sociais e ensaiar práticas alternativas coletivas. Isso implica não em desconsiderar os princípios freireanos, ao contrário, significa reafirmar os princípios fundantes. Por exemplo, uma educação que não se reconheça política, não pode ser de orientação freireana. Uma educação que não se faça desopacizadora dos mecanismos de preconceitos e racismos, longe estar de ser orientada pelos referenciais freireanos. Paulo Freire defende o diálogo como centro da educação que exige curiosidade, criticidade, amorosidade, conhecimento crítico e autonomia. Para ele, o acesso ao conhecimento começa pela leitura e compreensão do mundo como relação dialógica. Então, não poderia sua pedagogia ser objeto de memorização, repetição e coisificação do outro.

Entrevistadores: Paulo Freire é um dos autores mais respeitados e citados em todo o mundo, sobretudo no domínio da Educação de Pessoas Jovens e Adultas. Qual a sua posição sobre os contributos que o imortalizam? Na oportunidade poderia nos contar também sobre a interlocução do estudioso com os movimentos sociais?

Maria Eliete Santiago Paulo Freire inicia sua trajetória de professor atuando de forma institucional e como professor de aulas particulares, avulsas. Historicamente atuou no âmbito escolar e dos movimentos sociais e comunitários. Atuou no ensino, pesquisa e extensão de modo indicotomizável.

Os movimentos sociais em geral e o Movimento dos Trabalhadores Rurais Sem Terra - MST, em particular, reconhecem a contribuição de Paulo Freire e tomam seus referenciais teóricos e metodológicos como orientação para a prática político-pedagógico. O Centro de Formação Paulo Freire, no assentamento Normandia em Caruaru - Pernambuco, é uma grande exemplo de espaço formativo, de resistência política e de políticas e de preservação dos referenciais freireanos, assim como as Cátedras Paulo Freire. Entre elas, está a da Universidade Federal de Pernambuco - UFPE que nasce como reconhecimento institucional, preservação da memória e espaço de 
produção e socialização do conhecimento. Paulo Freire vive na sua proposta de educação como prática da liberdade, de gentificação da pessoa e no sonho coletivo de uma sociedade livre de toda forma de preconceito e racismo.

Entrevistadores: É notória a crescente produção científica e o volume de publicações relacionadas a Paulo Freire, em especial nos últimos três anos com a aproximação do seu centenário. A senhora considera que as Universidades Públicas brasileiras estão engajadas efetivamente neste movimento, vinculando educação básica, movimentos sociais e educação popular?

Maria Eliete Santiago Historicamente, Paulo Freire é rejeitado e reivindicado. Em 2013 surgiu o movimento "Basta de Paulo Freire" que recebeu como resposta a reação de coletivos sociais, acadêmicos e sindicais que reafirmaram o lugar de Paulo Freire, Patrono da Educação Brasileira, no centro da cena política, educativa e pedagógica do Brasil e do Mundo.

Paulo Freire é o terceiro teórico mais citado em trabalhos acadêmicos do mundo em universidades da área de humanas, seu livro Pedagogia do Oprimido encontra-se entre os 100 livros mais solicitados em universidades de língua inglesa. É o único brasileiro a entrar no top 100 dos livros mais solicitados. Este reconhecimento local e planetário está registrado em múltiplas linguagens, em diferentes pontos e grupos distribuídos no mundo. O planeta testemunhou o reconhecimento ao professor brasileiro ao longo de 2021, ano do seu centenário.

Recentemente, se observa no Brasil uma crescente institucionalização de espaços que desenvolvem e socializam estudos sobre e com os referenciais freireanos. Entre as instituições criadas que difundem os referenciais freireanos está o Instituto Paulo Freire, com base no Brasil e ramificações no mundo inteiro. As Cátedras Paulo Freire em todas as regiões do Brasil, uma infinidade de grupos e núcleos de estudos e pesquisas. Um Centro Paulo Freire que realiza a cada dois anos um Colóquio Internacional, na cidade de Paulo Freire. 
Componentes curriculares foram e vem sendo criados por pro-reitorias de ensino como esforço político e acadêmico de socialização do pensamento freireano.

Entrevistadores: Paulo Freire é considerado o "Andarilho da Utopia", na superação das "situações-limite" e na busca dos "inéditos-viáveis". Como a senhora situa as andarilhagens, e por que o conservadorismo tem tanto medo de Paulo Freire?

Maria Eliete Santiago Paulo Freire andarilhou pelo mundo semeando palavras e sonhos. Resistência e esperança. Andarilhou praticando e aprofundando a educação como prática da liberdade. A educação na perspectiva freireana é reconhecidamente uma educação que tem como horizonte a justiça social e a humanização da pessoa humana e da humanidade. A educação é um ato político, portanto, orienta um projeto social e de educação que tenha como sonho coletivo um mundo melhor para todas as pessoas. Nessa disputa por um projeto de sociedade e de educação, a educação assume uma posição estratégica: uma educação que não tem/não permite discursos discriminatórios e criminalização epistemológica.

Desse modo, Paulo Freire, em razão do seu engajamento, seu compromisso e sua práxis transformadora, não poderá ser aceito/recepcionado por aquelas/aqueles que não tenham/sonhem um projeto social transformador, de emancipação humana.

Entrevista concedida em novembro de 2021. 